\title{
EFEITO DE FUNGICIDAS E INFLUÊNCIA DE FATORES CLIMÁTICOS SOBREA MANCHA MANTEIGOSA NO CAFEEIRO
}

\author{
Effect of fungicides and influence of climatic factors on the blister spot of coffee trees
}

\author{
Josimar Batista Ferreira ${ }^{1}$, Mario Sobral de Abreu², Igor Souza Pereira ${ }^{3}$, \\ Katiucia Dias Fernandes ${ }^{4}$, Ricardo Borges Pereira ${ }^{5}$
}

\begin{abstract}
RESUMO
Neste trabalho, objetivou-se avaliar a eficiência de alguns fungicidas no controle da mancha manteigosa (Colletotrichum gloeosporioides) do cafeeiro (Coffea arabica $\mathrm{L}$.) em campo, e verificar os efeitos climáticos no progresso da doença. Foram conduzidos ensaios sobre cafeeiros da cultivar Catucaí Vermelho, com aproximadamente 8 anos de idade. Os fungicidas testados foram: tetraconazol, triadimenol, chlorotalonil e mancozeb, nas dosagens de $1,0 \mathrm{~L} / \mathrm{ha}, 12 \mathrm{Kg} / \mathrm{ha}, 3 \mathrm{Kg} / \mathrm{ha}$ e $2 \mathrm{Kg} / \mathrm{ha}$, respectivamente. Coletaram-se dados climáticos diariamente, no período de outubro de 2004 a maio de 2006. Os fungicidas chlorotalonil e triadimenol foram os que proporcionaram os melhores resultados de eficiência de controle do progresso de morte de ramos e frutos, destacando a produção de frutos cereja. Entre os meses de outubro a janeiro, verificou-se elevado progresso de mortes de ramos influenciado pelas altas precipitações pluviais. Os fungicidas tetraconazol e o mancozeb mostraram-se ineficientes. Plantas com mancha manteigosa, mesmo quando pulverizadas com fungicidas, tiveram significativa queda de frutos, enquanto plantas sadias apresentaram produções $95 \%$ superiores àquelas.
\end{abstract}

Termos para indexação: Fungicidas, Colletotrichum gloeosporioides, Coffea arabica.

\begin{abstract}
The aim of this work was to assess the effect of selected fungicides on the control of coffee blister spot in the field and to verify the climatic effects on the progress of the disease. Trials were carried out with coffee plants of cultivar Catucaí Vermelho, approximately 8 years old. The fungicides tested were tetraconazol $(1 \mathrm{~L} / \mathrm{ha})$, triadimenol $(12 \mathrm{Kg} / \mathrm{ha})$, chlorothalonil $(3 \mathrm{Kg} / \mathrm{ha})$, and mancozeb (2Kg/ha). Climatic data were collected daily from October 2004 to May 2006. The fungicides chlorotalonil and triadimenol provided the best efficiency results on the control of the progress of die-back and the number of fruits, with an increase in the cherry production. The increase of die-back during the period from October to January was possibly induced by the rainfall. Tetraconazol and mancozeb were not efficient. Coffee trees affected by blister spot, even if treated with fungicides, had significant decrease in the fruit production and the untreated healthy trees had their yield $95 \%$ higher than of those treated.
\end{abstract}

Index terms: Fungicides, Colletotrichum gloeosporioides, Coffea arabica.

(Recebido em 21 de maio de 2007 e aprovado em 5 de dezembro de 2007)

\section{INTRODUÇÃo}

A mancha manteigosa causa declínio de lavouras cafeeiras, ocasionando acentuada redução na produção (FERREIRA et al., 2005). Os sintomas característicos da doença são aqueles observados em folhas, isto é, inicialmente, manchas de cor verde-clara de aspecto oleoso, menos brilhante que a superfície do tecido e, em estágios avançados, as manchas apresentam coloração verde-pálida a amarela e bordas irregulares. Já nos ramos e frutos, as lesões são menores, deprimidas, necróticas de cor marrom clara e bordas irregulares. Nos últimos anos, a mancha manteigosa tem revelado um agravante na sintomatologia, com grande número de ramos mortos provocando declínio vegetativo e, conseqüentemente, produtivo, pelo o não vingamento da flor e pela mumificação dos frutos (COSTA et al., 2003; FERREIRA et al., 2005).

O patossistema Colletotrichum-cafeeiro ainda é pouco explorado no Brasil, e pouco se conhece sobre os eventos da infecção desse patossistema, levando às

\footnotetext{
${ }^{1}$ Engenheiro Agrônomo, Doutor em Fitopatologia, Professor Adjunto - Centro Multidisciplinar/CMult. - Universidade Federal do Acre/UFAC - Estrada Canela Fina, Km 12, Gleba Formoso, Lote 245 - Colônia São Francisco - 69980-000 - Cruzeiro do Sul, AC - josimarferreira@gmail.com ${ }^{2}$ Engenheiro Agrônomo, Doutor em Fitopatologia, Professor Titular - Departamento de Fitopatologia/DFP - Universidade Federal de Lavras/UFLA - Cx. P.

3037 - 37200-000 - Lavras, MG - msabreu@ufla.br
${ }^{3}$ Engenheiro Agrônomo, Doutorando em Fitopatologia - Departamento de Fitopatologia/DFP - Universidade Federal de Lavras/UFLA - Cx. P. 3037 37200-000 - Lavras, MG - igoreloi@yahoo.com.br

${ }^{4}$ Engenheira Agrônoma - Departamento de Fitopatologia/DFP - Universidade Federal de Lavras/UFLA - Cx. P. 3037 - $37200-000$ - Lavras, MG katiucia@yahoo.com.br

${ }^{5}$ Engenheiro Agrônomo, Doutorando em Fitopatologia - Departamento de Fitopatologia/DFP - Universidade Federal de Lavras/UFLA - Cx. P. 3037 37200-000 - Lavras, MG - ricardoborgespereira@yahoo.com.br
} 
divergências sobre o uso ou não das medidas de controle. Historicamente, a literatura científica nacional diverge quanto aos danos ocasionados em cafeeiros por este patógeno. Há pesquisadores que consideram o gênero Colletotrichum associado ao cafeeiro como um patógeno primário, que ataca diretamente os tecidos da planta, provocando danos e perdas de produção, e outros que o consideram como um patógeno secundário. É certo, no entanto, que a ocorrência de Colletotrichum spp. é grave nas regiões cafeeiras do Brasil, face às perdas significativas pelo ataque do fungo em frutos verdes, que tornam-se mumificados e caem (CHEN, 2002; FERREIRA, 2004; FERREIRA et al., 2004, 2005; NECHET \& ABREU, 2002; OROZCO-MIRANDA, 2003; OROZCO-MIRANDA et al., 2002a,b).

A cultura do café vem sendo comprometida pela associação de espécies de Colletotrichum spp. em todos os estádios dos órgãos do cafeeiro: folhas, frutos, flores e ramos. Neste contexto, destaca-se a "mancha manteigosa", doença que acarreta perdas na produção, morte de ramos, queda e mumificação de flores e de frutos e, ainda, não se conseguiu obter o controle desta doença (FERREIRA, 2004; OROZCO, 2003). Desde sua aparição na Costa Rica, recomendava-se, como medida de controle, erradicar todas as plantas doentes. Apesar disso, novos casos da doença surgiram (VARGAS \& GONZÁLEZ, 1972). Atualmente, existem relatos da doença nos estados de Minas Gerais, São Paulo, Paraná, Espírito Santo, Rondônia e Amazonas, nas espécies $C$. arabica L. e C. canephora Pierre ex Froenher, nas cultivares Catucaí Vermelho e Amarelo, Rubi, Mundo Novo, Catuaí Vermelho e Conilon (FERREIRA, 2004).

Conduziu-se este trabalho, com o objetivo de avaliar a eficiência de alguns fungicidas no controle da mancha manteigosa de cafeeiros em campo, e verificar a influência climática sobre o progresso da doença.

\section{MATERIALE MÉTODOS}

Para este trabalho, foram testados quatro fungicidas que se enquadram em 3 grupos químicos (Tabela 1).
Dos quatro fungicidas testados (Tabela 1), um foi aplicado via solo (triadimenol) e os demais por pulverização (mancozeb, chlorotalonil e tetraconazol). As dosagens e as aplicações foram feitas de acordo com o produto (fabricante). Os produtos à base de mancozeb, chlorotalonil e tetraconazol foram aplicados a cada 45 dias, para o período de safra de outubro a maio. No caso do triadimenol, foram feitas apenas três aplicações em épocas estratégicas: início da fase chumbinho (logo após floração), fase de expansão (enchimento dos frutos) e fase "verde cana".

Dentre os fungicidas utilizados, o mancozeb é registrado para a cultura do café na dose de $2 \mathrm{Kg} / \mathrm{ha}$ para o controle de antracnose, ferrugem e cercosporiose. O tetraconazol e o triadimenol também são registrados para cultura do café, apenas para controle da ferrugem na dose de $1 \mathrm{~L} / \mathrm{ha}$ e $12 \mathrm{Kg} /$ ha, respectivamente. O triadimenol foi aplicado via solo, na dose de $3,40 \mathrm{~g}$ por planta de café. Já o chloratholonil não é registrado para a cultura do café, porém, possui registro para o controle da antracnose em melancia, pepino, melão e uva na dose de $3 \mathrm{Kg} / \mathrm{ha}$.

O delineamento utilizado foi o de blocos casualizados com três repetições, quatro fungicidas mais duas testemunhas "plantas doentes e sadias", com parcelas formadas por três plantas úteis. Foram marcados ramos nas plantas doentes, sendo dois de cada lado da linha de plantio, os quais foram avaliados em intervalos de 20 dias, contando-se o número de folhas, número de frutos, comprimento do ramo a partir do ramo ortotrópico. Avaliouse também o número de lesões em cerca de $4 \mathrm{~cm}^{2}$ de área foliar. Esta avaliação foi em uma única folha do ramo marcado, compreendendo somente folha em completo estádio de desenvolvimento. A metodologia de avaliação constou de duas medições de cerca de $2 \mathrm{~cm}^{2}$ quadrados, uma em cada lado da nervura central da folha. Para a medição da área de avaliação, foi delimitado, em papel "cartolina", um retângulo de $2 \mathrm{~cm}^{2}$, o qual foi colocado sobre a folha, contando-se o número de lesões dentro da área.

Tabela 1 - Fungicidas utilizados no controle da mancha manteigosa de cafeeiros em campo.

\begin{tabular}{lcclc}
\hline Nome comercial & I.A $^{1}$ & CIA $^{2}$ & \multicolumn{1}{c}{ Modo de ação } & Grupo químico \\
\hline Domark & Tetraconazol & $100 \mathrm{~g} / \mathrm{l}$ & Inibidor da síntese de ergosterol & Triazol \\
Photon & Triadimenol & $60 \mathrm{~g} / \mathrm{kg}$ & Inibidor da síntese de ergosterol & Triazol \\
Bravonil Ultrex & Chlorotalonil & $825 \mathrm{~g} / \mathrm{kg}$ & Multissítios & Aromáticos \\
Dithane & Mancozeb & $800 \mathrm{~g} / \mathrm{kg}$ & Inibidor de enzimas e proteínas & Ditiocarbamato \\
\hline
\end{tabular}

${ }^{1}$ Ingrediente ativo; ${ }^{2}$ Concentração do ingrediente ativo 
Foi também avaliada a produção de frutos cereja na safra de 2005/2006, exceto na safra 2004/2005 em virtude de baixa produção, decorrente da bienalidade aliada às más condições fisiológicas em que se encontravam as plantas doentes, apresentando majoritariamente produção nula.

Com base nos índices médios de incidência de $C$. gloeosporioides observados, calculou-se a área abaixo da curva de progresso da doença (AACPD), conforme equação proposta por Campell \& Madden (1990).

Os dados climáticos foram fornecidos pelo Setor de Agrometeorologia do Departamento de Engenharia (DEN) da UFLA, coletados diariamente, no período entre outubro de 2004 a maio de 2006. Dessa forma, obtiveramse as seguintes variáveis climáticas: precipitação $(\mathrm{mm})$, temperatura máxima $\left({ }^{\circ} \mathrm{C}\right)$ temperatura mínima $\left({ }^{\circ} \mathrm{C}\right)$, temperatura média $\left({ }^{\circ} \mathrm{C}\right)$, umidade relativa do ar $(\%) \mathrm{e}$ insolação diária (h). Com base nesses dados climatológicos, foram calculadas médias de 30 dias antes das datas de avaliações das doenças, exceto para precipitação, a qual considerou o volume total no período.

\section{RESULTADOS E DISCUSSÃO}

No período de monitoramento em campo, verificaram-se diferentes efeitos entre os fungicidas. Em relação à mortes de ramos, na safra 2004/2005, o triadimenol, reduziu o número médio de morte de ramos por planta, enquanto que, na safra 2005/2006, destacou-se o chlorotalonil (Figuras 2A e B) nesse quesito. Comparando-se os dois anos de avaliações, verificou-se maior progresso de morte de ramos no ano safra 2005/2006 (Figura 3), possivelmente em razão do prolongamento das chuvas (março e abril de 2006), em média, 290,2 mm, contra $163,2 \mathrm{~mm}$, no mesmo período do ano anterior (Figura 1). Ferreira (2004) observou no mesmo período do ano de 2003, média pluviométrica de 70,1 mm para a mesma região do experimento.

Portanto, houve uma interação positiva entre precipitação pluviométrica com o progresso de morte de ramos, fato observado nos dois anos de avaliações. Mesmo naquelas plantas onde não se realizou pulverizações verificaram-se altos índices de morte de ramos com média $34 \%$ (Figura 1), apontando uma influência direta da precipitação na morte de ramos de cafeeiros com mancha manteigosa (C. gloeosporioides), o que não é nenhuma novidade nem para o café (COOK 1975; FERREIRA, 2004) nem para qualquer outra cultura suscetível (DODD et al., 1992).

No período de monitoramento (safra 2004/2005 e 2005/2006), verificaram-se padrões similares da morte de ramos (Figura 2). No período de outubro a janeiro, ocorreu maior progresso desse sintoma, com máximo no mês de dezembro, período com precipitação de $279,3 \mathrm{~mm}$, temperatura máxima (média de $27,7^{\circ} \mathrm{C}$ ) e umidade relativa (média de 80\%) (Figuras 1 e 4).

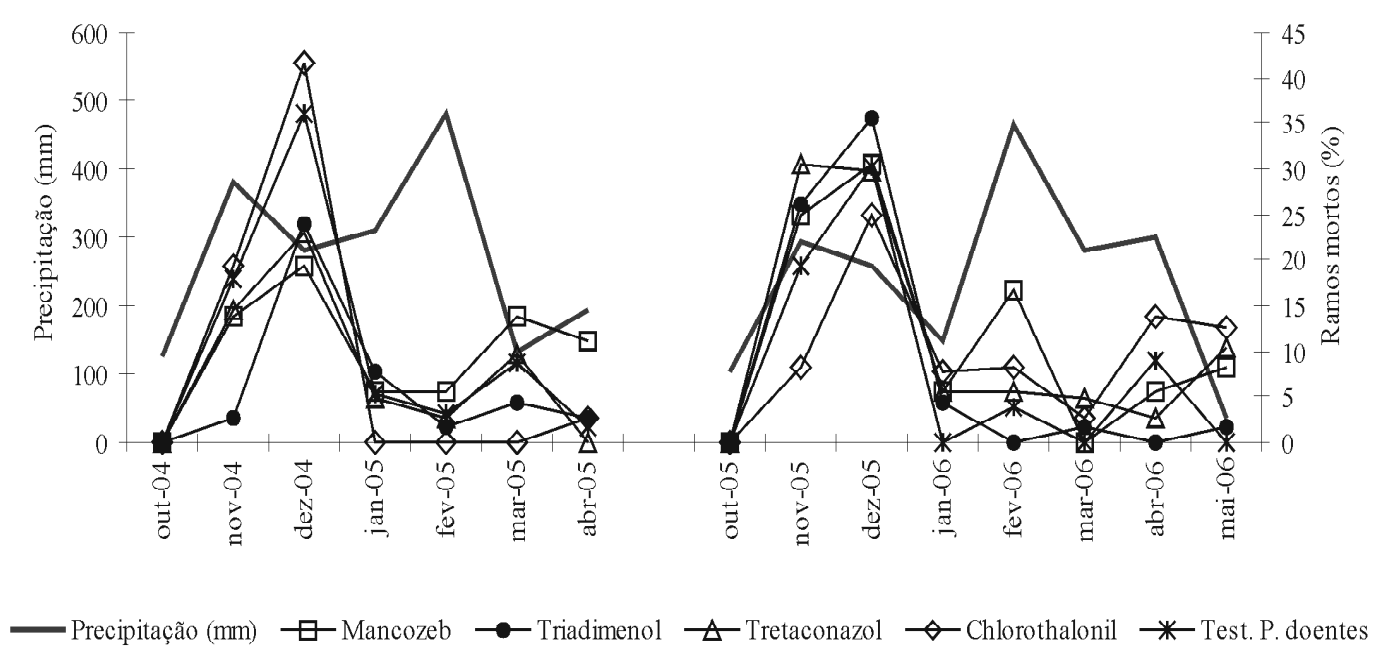

Figura 1 - Regime de chuvas e morte de ramos de cafeeiro com mancha manteigosa, frente a diferentes fungicidas $(\mathrm{A}=$ safra 2004/2005) (B= safra 2005/2006). 


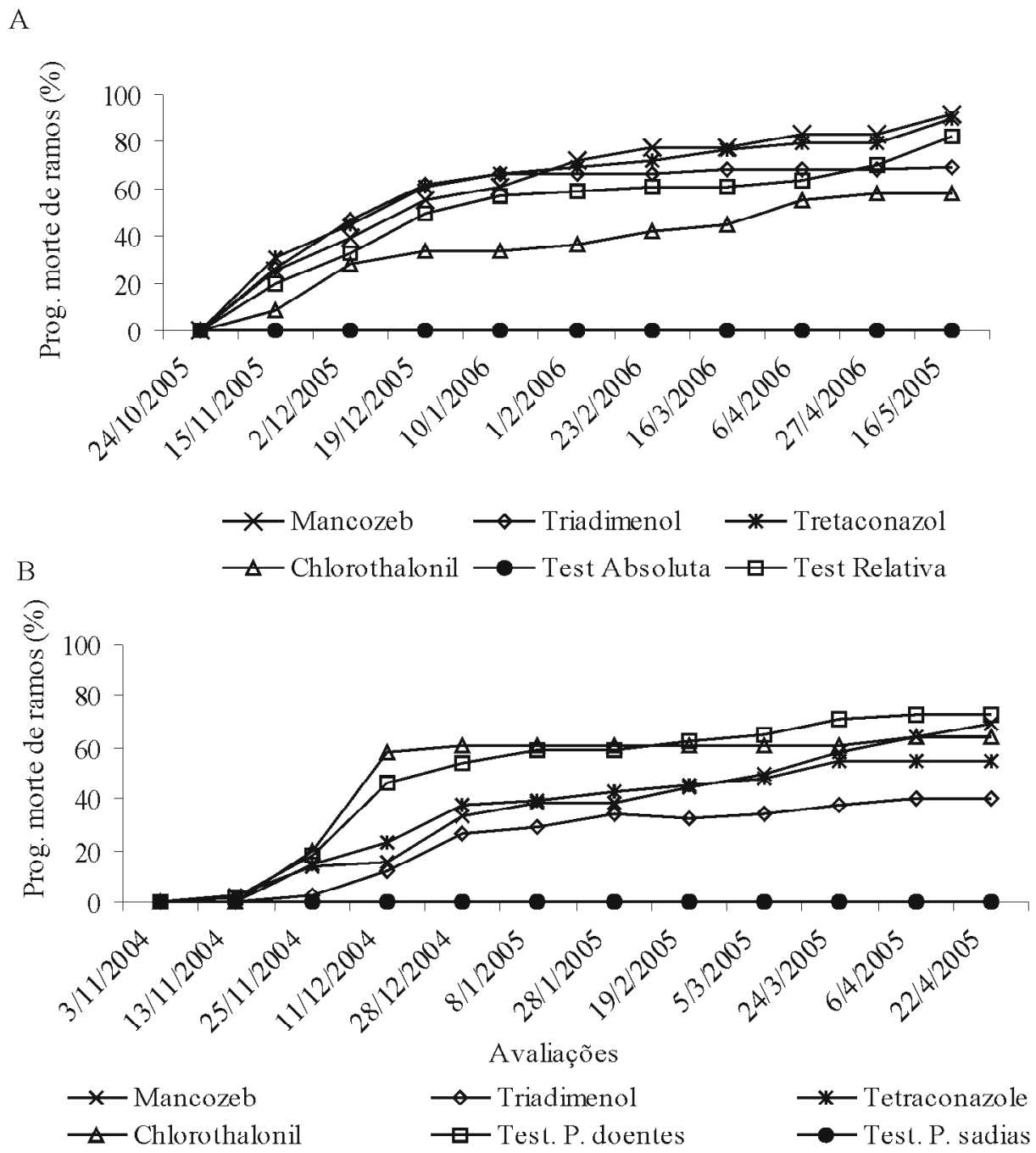

Figura 2 - Progresso da morte de ramos por planta de cafeeiro com sintomas de mancha manteigosa, no período de nov./ 2004 a maio/2006 com diferentes fungicidas ( $\mathrm{A}=$ nov./04 a abr./05) $(\mathrm{B}=$ out./05 a maio/06).

Segundo Ferreira (2004) e Ferreira et al. (2004), ataques intensos nas folhas e ramos novos estão relacionados com a fase de maior vegetação, correspondendo ao período quente e chuvoso, de outubro a fevereiro. No presente trabalho, correlaciona-se também a morte de ramos com a fase de enchimento de frutos (chumbinho), fase de intensos processos fisiológicos.

Ferreira (2004) já apontava em seus estudos de progresso da antracnose em folhas de cafeeiro que as maiores incidências de espécies de Colletotrichum nesses tecidos estão correlacionadas a altas precipitações.

Pela análise da área abaixo da curva de progresso da morte de ramos (AACPMR), observa-se que, no período de
2004/2005, o triadimenol em aplicações via solo, foi o fungicida mais eficiente na redução da morte de ramos por C. gloeosporioides em plantas com mancha manteigosa, em comparação com as parcelas tratadas com tetraconazol, chlorotalonil e o mancozeb. Nestas, houve efeito semelhante na redução de mortes de ramos e, em relação ao ano safra 2005/2006, destacou-se o chlorotalonil, seguido pelo triadimenol, mancozeb e tetraconazol (Figura 3).

Segundo Salustiano et al. (2002), em testes de campo, o triadimenol não demonstrou tanta efetividade na redução de antracnose causada por Colletotrichum spp. em frutos de café. Por outro lado, Ferreira et al. (2005) observaram que o triadimenol, em aplicações via solo, foi 


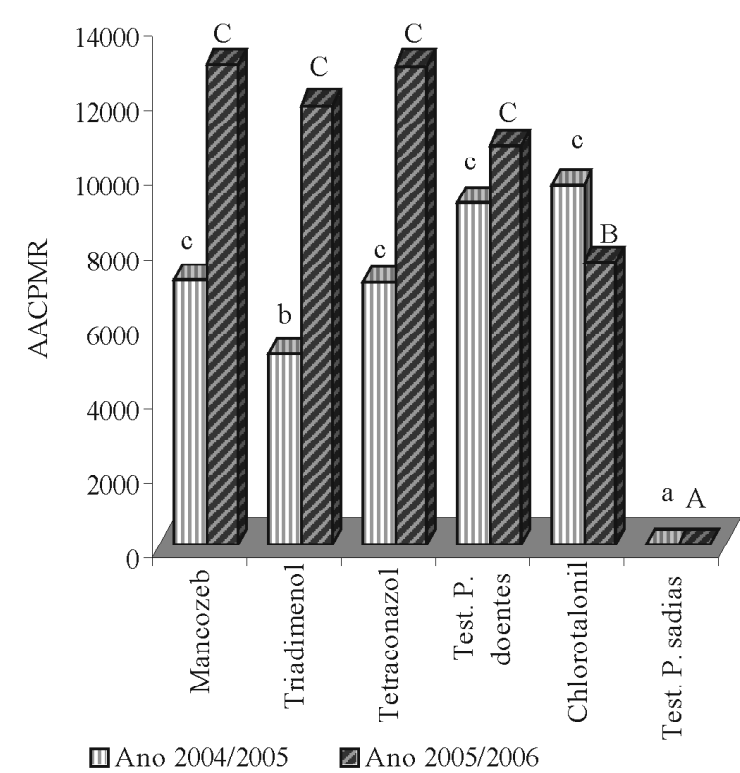

Figura 3 - Áreas abaixo da curva de progresso da morte de ramos (AACPMR) do cafeeiro com sintomas de mancha manteigosa, no período de nov./2004 a maio/2006, frente a diferentes fungicidas. (Médias seguidas pela mesma letra não diferem entre si, pelo teste de Tukey ao nível de 5\% de probabilidade).

o fungicida mais eficiente na redução da morte de ramos por C. gloeosporioides em plantas com mancha manteigosa.

Quando avaliados o crescimento médio de ramos, o número médio de folhas por ramos e o número médio de lesões em $4 \mathrm{~cm}^{2}$ de folhas, não se verificou efeito significativo do controle pelos fungicidas. Contudo, verificou-se o aumento médio no crescimento de ramos e no número médio de folhas. Verificou-se aumento do número médio de lesões por folhas ao longo do tempo, com maior evidência nas plantas não pulverizadas (testemunha). Na safra 2005/2006, verificou-se menor número de lesões, comparada à safra 2004/2005, porém, não houve diferenças entre os fungicidas com o decorrer das avaliações e pulverizações.

Em busca de alternativas para o manejo de $C$. gloeosporioides isolado de mancha manteigosa, vários pesquisadores realizaram recepas baixas em plantas doentes, porém, não obtiveram sucesso no controle. Concluíram que, em plantas com os sintomas da doença, essa estratégia não colabora para a eliminação do patógeno, pois este coloniza o sistema vascular das plantas doentes (FERREIRA, 2004; OROZCO, 2003; PEREIRA, 2005; PEREIRA et al., 2005). Inferiram que o uso de fungicidas de contato poderia ter pouco efeito no controle e que fungicidas sistêmicos poderiam proporcionar melhores resultados. Segundo Vargas \& González (1972), na Costa Rica, como medida de controle recomendavam erradicar todas as plantas doentes. Apesar disso, surgiam novos casos.

No período de avaliações, quantificou-se o número de frutos por ramos ao longo do tempo (Tabela 2). No primeiro ano do estudo (safra 2004/2005), não se verificou efeito significativo entre os fungicidas, apenas quando comparados com o número de frutos em ramos de plantas sadias (sem pulverizações) (Tabela 2), tal fato deve-se ao estado debilitado em que se encontravam as plantas, tendo poucas respostas de controle da queda de frutos. Em plantas com mancha manteigosa observou-se significativa queda de frutos. Na safra 2004/2005, com relação ao progresso de frutos em plantas doentes, verificou-se que o triadimenol e o chlorotalonil foram os mais promissores, apresentando, em média, 6 e 4 frutos/ramos nas últimas avaliações, respectivamente, seguidos pelo mancozeb e o tetraconazol, com 2 e 1 frutos/ramos, enquanto que, nas plantas doentes sem pulverizações, não existiam frutos nos ramos (Tabela 2).

No ano safra 2005/2006, verificou-se um maior número de frutos, quando comparado ao ano anterior (ano de alta carga pendente), apresentando, nas primeiras avaliações, média de 943 frutos chumbinho por ramos em plantas sadias e média de 339 frutos em plantas doentes não pulverizadas. Observou-se, nas plantas doentes tratadas, maior número de frutos chumbinho para o tratamento com triadimenol (578 frutos), seguido pelos tratamentos com tetraconazol e chlorotalonil (287 e 237 frutos, respectivamente) (Tabela 2).

No segundo ano, verificaram-se efeitos significativos entre os fungicidas, pela análise da área abaixo da curva de progresso de frutos (AACPF). O triadimenol se destacou, seguido pelo chlorotalonil tendo o mancozeb a menor AACPF. Nas ultimas avaliações não existiam frutos nos ramos tratados com mancozeb e com tetraconazol. Já o triadimenol e o chlorotalonil apresentaram em média, 7 e 4 frutos/ramos, respectivamente (Tabela 2). Neste último ano foi avaliada a produção média por tratamento. Entre os fungicidas testados, destacou-se o triadimenol, seguido pelo chlorotalonil, com médias de $535 \mathrm{~g}$ e $483 \mathrm{~g}$ respectivamente, tendo o mancozeb a menor produção com 90,66g, seguido pelo tetraconazol, com $157 \mathrm{~g}$, ambos com produções inferiores a das plantas doentes 
Tabela 2 - Progresso do número de frutos em ramos e produções médias de plantas de cafeeiro Coffea arabica L. com sintoma da mancha manteigosa submetidas a diferentes fungicidas, no período de nov. 2004 a maio/2006.

\begin{tabular}{|c|c|c|c|c|c|c|c|c|c|c|c|c|c|c|c|}
\hline \multicolumn{16}{|c|}{ Ano Safra - 2004/2005 } \\
\hline \multicolumn{16}{|c|}{ Avaliações } \\
\hline Trat. & 1 & 2 & 3 & 4 & 5 & 6 & 7 & 8 & 9 & 10 & 11 & 12 & Média ${ }^{1}$ & $\mathrm{AACPF}^{2}$ & Prod. $^{3}$ \\
\hline Manc. & 182 & 125 & 65 & 41 & 22 & 16 & 7 & 4 & 2 & 2 & 2 & 2 & $39 \mathrm{~b}$ & $5432 \mathrm{~b}$ & - \\
\hline Triad. & 115 & 75 & 40 & 30 & 21 & 16 & 12 & 11 & 10 & 8 & 7 & 6 & $29 \mathrm{~b}$ & $4331 \mathrm{~b}$ & - \\
\hline Tetra. & 91 & 69 & 48 & 27 & 16 & 6 & 4 & 3 & 1 & 1 & 1 & 1 & $22 \mathrm{~b}$ & $3214 \mathrm{~b}$ & - \\
\hline Chloro. & 164 & 99 & 52 & 16 & 11 & 6 & 5 & 4 & 4 & 4 & 4 & 4 & $31 \mathrm{~b}$ & $4070 \mathrm{~b}$ & - \\
\hline T.P.D & 203 & 99 & 59 & 22 & 12 & 5 & 2 & 1 & 1 & 1 & 0 & 0 & $34 \mathrm{~b}$ & $4224 \mathrm{~b}$ & - \\
\hline T.P.S & 362 & 345 & 344 & 322 & 322 & 321 & 304 & 303 & 291 & 278 & 265 & 261 & $310 \mathrm{a}$ & $55430 \mathrm{a}$ & - \\
\hline \multicolumn{16}{|c|}{ Ano Safra - 2005/2006 } \\
\hline Manc. & 175 & 70 & 29 & 14 & 3 & 0 & 0 & 0 & 0 & 0 & 0 & - & $27 \mathrm{c}$ & $4161 \mathrm{c}$ & $90,6 \mathrm{~d}$ \\
\hline Triad. & 578 & 185 & 72 & 42 & 17 & 12 & 8 & 9 & 9 & 7 & 7 & - & $86 \mathrm{~b}$ & $13437 \mathrm{ab}$ & $535,0 \mathrm{~b}$ \\
\hline Tetra. & 287 & 110 & 29 & 9 & 2 & 2 & 1 & 0 & 0 & 0 & 0 & - & $40 \mathrm{bc}$ & $6098 \mathrm{~b}$ & $157,0 \mathrm{c}$ \\
\hline Chlor. & 237 & 174 & 89 & 65 & 51 & 25 & 15 & 12 & 6 & 4 & 4 & - & $62 \mathrm{~b}$ & $11293 b$ & $483,0 \mathrm{~b}$ \\
\hline T.P.D & 339 & 161 & 99 & 62 & 31 & 5 & 6 & 6 & 3 & 1 & 1 & - & $65 \mathrm{~b}$ & $10882 \mathrm{~b}$ & $223,0 \mathrm{c}$ \\
\hline T.P.S & 943 & 930 & 927 & 887 & 868 & 741 & 737 & 737 & 696 & 693 & 692 & - & $805 \mathrm{a}$ & $164766 \mathrm{a}$ & $10960,3 \mathrm{a}$ \\
\hline
\end{tabular}

Dados transformados $\log _{(\mathrm{X})}{ }^{1} \mathrm{CV}=50,87 \% ; \mathrm{CV}=50,10 \% ;{ }^{2} \mathrm{CV}=9,93 \% \mathrm{CV}=9,24 \% ;{ }^{3}$ produções média(g) em três plantas $\mathrm{CV}=29,87 \%$. Médias seguidas pela mesma letra na coluna não diferem entre si, pelo teste de Tukey (pd"0,05). Manc.= mancozeb; Triad. $=$ triadimenol; Tetra $=$ tetraconazol; Chlor $=$ chlorotalonil; T.P.D. $=$ testemunha plantas doentes; T.P.S.= testemunha planta sadia.

não pulverizadas, com média de $223 \mathrm{~g}$ (Tabela 2). Esta produção (plantas doentes não pulverizadas) maior do que em algumas plantas tratadas, talvez se deva a uma menor queda de frutos ao longo do tempo, pois, na última avaliação verificou-se, em média, 1 fruto/ramo (Tabela 2). Mesmo com as aplicações em plantas doentes (duas safras consecutivas), quando se comparam produções de plantas sadias (sem sintoma da mancha manteigosa) com produções de plantas doentes, verifica-se uma enorme diferença, em torno de $95 \%$ (Tabela 2).

Nestas observações de campo, um agravante revelou-se na sintomatologia da doença. Mesmo naquelas plantas que sofreram tratamento químico por fungicidas, constatou-se um forte definhamento, com grande número de ramos mortos, provocando declínio vegetativo e, conseqüentemente, produtivo, com altos percentuais de quedas de frutos.

Ferreira et al. (2004) já haviam descritos ataques intensos em folhas e ramos novos em plantas adultas, ocorrendo necrose e seca dos ramos na parte apical, levando à morte das plantas de forma descendente.
Esses ataques severos observados estão relacionados à fase de maior vegetação, correspondendo ao período quente e chuvoso, de outubro a fevereiro (Figuras $4 \mathrm{e}$ 1). Com isso, a produção é afetada chegando a ser nula (COSTA et al., 2003; FERREIRA, 2004; FERREIRA et al., 2004).

Monitorando a mancha manteigosa em campo, Ferreira (2004) verificou que, naquelas plantas com esses sintomas, foi possível observar declínio vegetativo e, conseqüentemente, produtivo, ramos plagiotrópicos com internódios curtos, florescimento sem sobrevivência, acarretando em baixos percentuais de chumbinho, e mumificação com o desenvolvimento e crescimento destes frutos. Durante os dois anos de monitoramento, houve perda significativa de produção, a qual chegou a ser nula em algumas plantas. Plantas recepadas tiveram suas brotações atrofiadas e, à medida que emitiam novas brotações, surgiam também sintomas da doença. Ferreira (2004) e Ferreira et al. (2004), por meio de estudos de colonização nos ovários, observaram que as plantas com sintomas de mancha manteigosa foram mais suscetíveis 

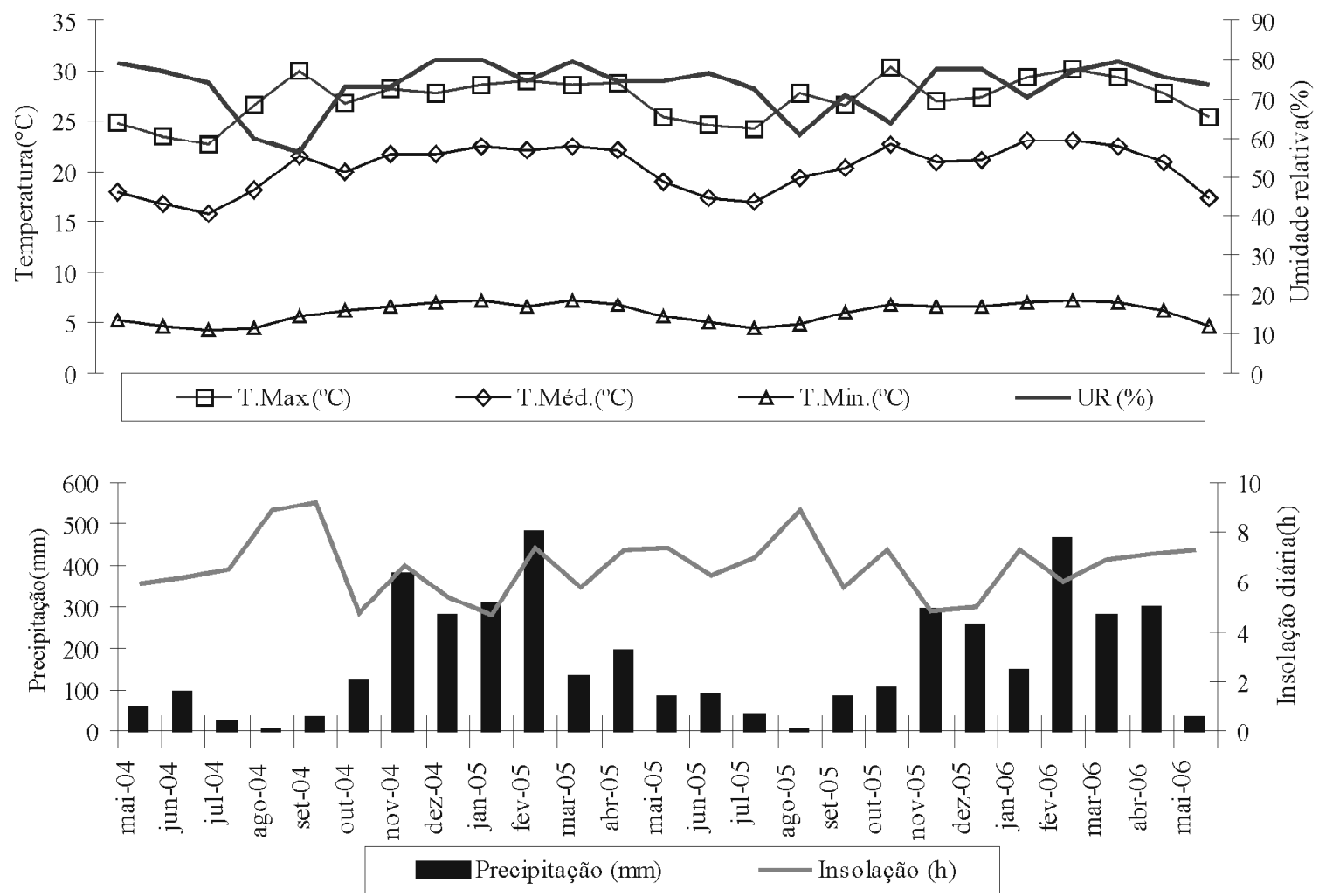

Figura 4 - Variáveis climáticas monitoradas no período de maio/2004 a maio/2006.

ao C. gloeosporioides, com média de $27,91 \%$, enquanto as plantas sem sintomas tiveram média de $5,83 \%$.

\section{CONCLUSÕES}

O mancozeb foi ineficiente no controle da doença, já os fungicidas chlorotalonil e triadimenol, considerandose o progresso de morte de ramos, o número de frutos/ ramos e a produção de frutos cereja, foram os que proporcionaram os melhores resultados de eficiência, porém sem o controle satisfatório da doença. Quando se compararam produções de plantas doentes com as de plantas sadias, verifica-se uma acentuada diferença (cerca de 95\%). Observou-se também, influência direta da precipitação pluviométrica com a morte de ramos em plantas com mancha manteigosa, pois os maiores índices de morte de ramos coincidiram entre os meses outubro a fevereiro, período de maior índice pluviométrico. Portanto, confirmouse a complexidade deste patossistema, visão que até o momento não obteve sucesso no controle da doença. Novas formulações devem ser testadas, combinando épocas de aplicação, periodicidade e dosagens de produtos.

\section{REFERÊNCIAS BIBLIOGRÁFICAS}

CAMPBELL, C. L.; MADDEN, L. V. Introduction to plant disease epydemiology. New York: J. Wiley, 1990. $532 \mathrm{p}$.

\section{CHEN, Z. Morphocultural and pathogenic} comparisons between Colletotrichum kahawae and Colletotrichum gloeosporioides isolated from coffee berries. 2002. 163 f. Tese (Doutorado em Engenharia Agronômica) - Instituto Superior de Agronomia da Universidade Técnica de Lisboa, Lisboa, 2002.

COOK, R. T. A. The effect of weather conditions on infection by coffee berry disease. Kenya Coffee, Nairobi, v. 40, n. 2, p. 190-197, June 1975.

COSTA, H.; VENTURA, J. A.; FERRÃO, M. A. Mancha manteigosa em café arábica na região serrana do Estado do Espírito Santo. In: SIMPÓSIO DE PESQUISA DOS CAFÉS DO BRASIL, 3., 2003, Porto Seguro, BA Anais... Porto Seguro: [s.n.], 2003. p. 206. 
DODD, J. C.; ESTRADA, A.; JEGER, M. J. Epidemiology of Colletrotrichum gloeosporioides in the tropics. In: BAILEY, J. A.; JEGER, M. J. (Eds.). Colletrotrichum biology, pathology and control. Wallingford: $\mathrm{CAB}$ International, 1992. p. 308-325.

FERREIRA, J. B. Flutuação Sazonal e associação de Colletotrichum gloeosporioides Penz. a diferentes órgãos e tecidos cafeeiros (Coffea arabica L.). 2004.90 p. Dissertação (Mestrado em Fitopatologia) Universidade Federal de Lavras, Lavras, 2004.

FERREIRA, J. B.; PEREIRA, I. S.; FERNANDES, K. D.; ABREU, M. S. Prejuízos ocasionados pela mancha manteigosa em cafeeiros (Coffea arabica L.). In: ENCONTRO SUL MINEIRO DE CAFEICULTURA, 10; SIMPÓSIO DE PESQUISA CAFEEIRA DO SUL DE MINAS, 5., 2004, Lavras. Anais... Lavras: Necaf, 2004. CD-ROM.

FERREIRA, J. B.; SILVA, E. H.; FERNANDES, K. D.; PEREIRA, R. B.; ABREU, M. S.; PEREIRA, I. S. Efeito de fungicidas no controle da seca de ramos do cafeeiro $(C$. arabica L.) com mancha manteigosa (Colletotrichum spp.). Fitopatologia Brasileira, Brasília, v. 30, p. 111, ago. 2005. Suplemento.

NECHET, K. L.; ABREU, M. S. Caracterização morfológica e testes de patogenicidade de isolados de Colletotrichum sp. obtidos de cafeeiro. Ciência e Agrotecnologia, Lavras, v. 26, n. 6, p. 1135-1142, nov./ dez. 2002.

OROZCO-MIRANDA, E. F. Caracterização morfológica, molecular, bioquímica e patogênica de isolados de Colletotrichum spp. associados ao cafeeiro em Minas Gerais e Comparação com Colletotrichum kahawae. 2003. 147 p. Tese (Doutorado em Fitopatologia) Universidade Federal de Lavras, Lavras, 2003.
OROZCO-MIRANDA, E. F.; FREITAS, M.; PIGOZZO, P.; ABREU, M. S. Estudo da transmissão de Colletotrichum spp. por sementes de café arabica (Coffea arabica). In: CONGRESSO DE PÓSGRADUAÇÃO, 11., 2002, Lavras, MG. Resumos... Lavras: UFLA/APG, 2002a.

OROZCO-MIRANDA, E. F.; FREITAS, M.; PIGOZZO, P.; ABREU, M. S. Incidência de Colletotrichum spp. em frutos cereja e sementes de café arabica (Coffea arabica) no estado de Minas Gerais. In: CONGRESSO DE PÓSGRADUAÇÃO, 11., 2002, Lavras, MG. Resumos... Lavras: UFLA/APG, $2002 b$.

PEREIRA, I. S. Compatibilidade vegetativa e sexual do complexo Glomerella-Colletotrichum associado ao cafeeiro e estudos histopatológicos. 2005. 92 p.

Dissertação (Mestrado em Fitopatologia) - Universidade Federal de Lavras, Lavras, 2005.

PEREIRA, I. S.; FERREIRA, J. B.; ABREU, M. S.

Histologia de ramos de cafeeiro (Coffea arabica L.) com mancha manteigosa causada por Colletotrichum spp. In: SIMPÓSIO DE PESQUISA DOS CAFÉS DO BRASIL, 4., 2005, Londrina. Anais... Londrina: CBP\&D-Café-PR, 2005. v. 4. CD-ROM.

SALUSTIANO, M. E.; OROZCO, M. E.; ABREU, M. S. E.; POZZA, E. A. Efeito de fungicidas recomendados para o controle de ferrugem do cafeeiro sobre Colletotrichum spp. In: CONGRESSO DE PÓS GRADUAÇÃO, 2002, Lavras, MG. Anais... Lavras: UFLA, 2002.

VARGAS, G. E.; GONZALEZ, U. L. C. La mancha mantecosa del café causada por Colletotrichum spp. Turrialba, San José, v. 22, n. 2, p. 129-135, 1972. 